\title{
The Shoreline Environment Aerosol Study (SEAS): A Context for Marine Aerosol Measurements Influenced by a Coastal Environment and Long-Range Transport*
}

\author{
Antony D. Clarke and Vladimir N. Kapustin \\ Department of Oceanography, University of Hawaii at Manoa, Honolulu, Hawaii
}

(Manuscript received 16 July 2002, in final form 14 February 2003)

\begin{abstract}
The Shoreline Environment Aerosol Study (SEAS) was carried out in Hawaii on the southeast coast of Oahu in an area exposed to relatively steady onshore flow. This location provided favorable opportunities to test and evaluate new instrumentation designed to improve measurements of marine aerosol and its physical, chemical, and optical properties, including the remote sensing (lidar) of coastal aerosol fields. Data acquired from the diverse instruments deployed before and during SEAS demonstrate that environmental and meteorological features actively influence aerosol measurements at this location. Both a ceilometer and a visibility sensor were operated continuously and found to be effective autonomous tools for characterizing mixed-layer aerosol conditions. These instruments also helped demonstrate that changes in physical and optical properties measured during SEAS were also linked to volcanic aerosol transported across the Pacific in the free troposphere from Japan and later entrained into the marine boundary layer. This and various local effects of wind direction, wind speed, tides, and sampling altitude were superimposed on the variations in offshore marine aerosol. Characterization of these site-specific effects provides a context and guidance for the interpretation of coastal aerosol data and evaluation of SEAS data.
\end{abstract}

\section{Introduction}

The Shoreline Environment Aerosol Study (SEAS) was carried out at Bellows Air Force Station (BAFS) on the southeast coast of Oahu, Hawaii, 21-30 April 2000 (Fig. 1). SEAS was designed as an intensive study to bring together various Office of Naval Research (ONR)-funded investigators with new instrumentation developed to enhance our capabilities in characterizing the physical, chemical, and optical properties of oceanic and coastal aerosol. The SEAS focus was on the measurement of marine aerosol properties because these play an important role in many atmospheric processes, including visibility, optical propagation, remote sensing, cloud/haze formation, and radiative transfer in the atmosphere. In unpolluted regions close to the ocean's surface a large portion of this aerosol consists of sea salt and related constituents that are generated by wavewind interaction. It was expected that the SEAS location and sample period would provide a fairly stable environment for the study of marine aerosol such that in-

\footnotetext{
* School of Ocean and Earth Science and Technology Contribution Number 6065.
}

Corresponding author address: Dr. Antony D. Clarke, Dept. of Oceanography, University of Hawaii at Manoa, 1000 Pope Rd., MSB 501, Honolulu, HI 96822.

E-mail: tclarke@soest.hawaii.edu strument performance could be evaluated with minimum concerns about aerosol variability. Even so, both longrange transport and local coastal characteristics were found to influence marine aerosol concentration and optical effects observed during SEAS.

The University of Hawaii (UH) atmospheric research site at BAFS provided a secure instrumented tower $(20$ $\mathrm{m})$, research laboratories, coastal location, clean marine air, and onshore flow (Fig. 1). The tower includes staging areas at several heights and is enclosed by a fence that accommodates three or four container laboratories. During SEAS these included the lidar van on the ocean side of the compound, a portable aerosol research van, a visitor research container, and another UH research container. The sandy shore is almost orthogonal to the prevailing trade winds, and a shallow reef is located about $1 \mathrm{~km}$ offshore, where breaking wave activity generally occurs (Fig. 1). This breaking-wave region often extends farther north and south along the coast than is evident in the reef region (circled) as a result of wind, tide, and swell variations. A somewhat deeper lagoon between the reef and shore tends to suppress subsequent breaking waves up to a few meters away from the shoreline. This lagoon region allows aerosol produced in the "reef" region to evolve and mix during transport onshore. The remaining wave energy is also dissipated on the shoreline over about a $25-\mathrm{m}$ distance to create aerosol generally confined to below $10-\mathrm{m}$ altitude at the tower location (Clarke et al. 2003; Porter et al. 2003). 

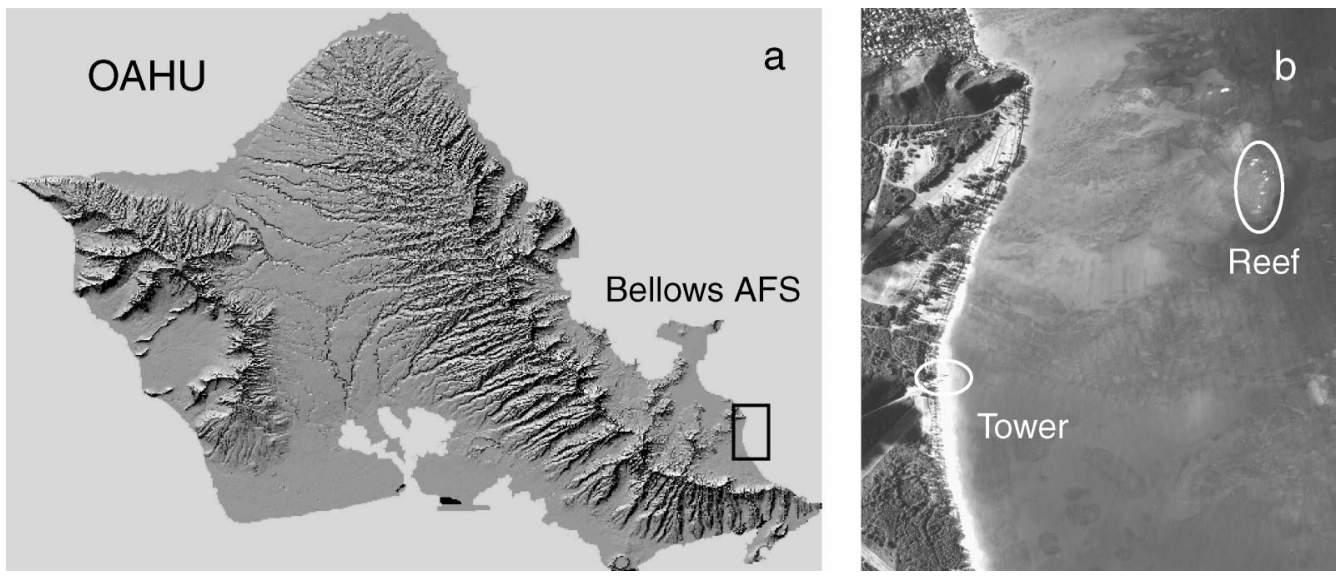

FIG. 1. (a) Map of the island of Oahu and (b) a photo image showing the UH BAFS tower and SEAS coastal research site location.

\section{Participants}

Several SEAS investigators from the University of Hawaii had previously cooperated on measurements at the BAFS site. Some measurements included the scanning 3D aerosol lidar built to explore the nature of coastal aerosol plumes (Porter et al. 2000). During horizontal scans the lidar mapped out the horizontal structure of plumes evolving downwind from regions of breaking waves. During vertical scans it provided information on plume development and lofting. Interpretation and validation of the lidar signal were part of the SEAS effort (Porter et al. 2003). Part of this assessment was facilitated by determination of the aerosol scattering phase function using a new polar nephelometer evaluated for this study (Lienert et al. 2003). This also included its application to retrieving size distributions through inversion for comparison to observations. Periods influenced by breaking waves and unperturbed periods together provided bounds and validation for the observed range in lidar extinction measured $300-400 \mathrm{~m}$ offshore. Aerosol size distributions with diameters between 0.010 and $10 \mu \mathrm{m}$ were measured in conjunction with their related optical properties and provided an independent evaluation of lidar performance (Clarke et al. 2003). These measurements also included thermal analysis (Clarke 1991) over much of this range that provided new information on sea-salt contributions to particle sizes down to $20 \mathrm{~nm}$. Other commercial autonomous instruments (i.e., the Vaisala visibility probe and ceilometer) designed to provide continuous characterization of the in situ aerosol in airport settings were also evaluated during SEAS for their utility for remote marine deployment.

In addition to UH investigators, SEAS included a number of participants from other institutions (Table 1). Evaluation of aerosol sizes retrieved through mathematical inversion of lidar data (Shifrin and Zolotov 2003) was carried out at Oregon State University. Additional measurements of aerosol light absorption and scattering were made by the University of Washington (UW), including direct aerosol backscatter measurements using their new $180^{\circ}$-backscatter nephelometer, which yields the extinction-to-backscatter ratio, or lidar ratio, of the SEAS aerosol (Masonis et al. 2003). These data were evaluated in terms of marine aerosol properties and interpreted in conjunction with size distribution data and results modeled from Mie theory (Masonis et al. 2003). A new instrument from the University of Miami combined size discrimination with flame photometric emission detection of sodium to determine the size-resolved sea-salt concentrations down to diameters of about $0.25 \mu \mathrm{m}$ (CampuzanoJost et al. 2003), which were then compared with distributions inferred from a volatility technique (Clarke et al. 2003). The details and results of these experiments are presented elsewhere in this issue and will not be presented here. Below we will provide a context for the measurements in SEAS that include data collected before and during the SEAS campaign.

The SEAS experiment also provided an opportunity for other investigators developing prototype instruments to evaluate their performance in association with the extensive characterization available during SEAS. These included tests of a new bistatic polar nephelometer and gas phase measurements not reported here.

\section{In situ autonomous characterization of the SEAS aerosol environment}

The provision of in situ measurements of aerosol properties was considered to be a valuable supportive dataset for providing a context for SEAS. Two new in situ instruments were deployed to support SEAS by continuously monitoring the aerosol environment. Because these were new commercial products designed for autonomous airport deployment and not tested in remote regions, we report on their performance here. A Vaisala ceilometer (CT25K) was mounted on our portable laboratory at BAFS (Fig. 2) as a means of continuously measuring the 
TABLE 1. SEAS investigators, instrumentation, and sampling location.

\begin{tabular}{|c|c|c|}
\hline Investigators & Instrument & Location \\
\hline $\begin{array}{l}\text { S. Sharma, }{ }^{a} \text { B. Lienert, }{ }^{a} \\
\text { J. Porter }\end{array}$ & $\begin{array}{l}\text { Scanning lidar backscatter/extinction at wavelengths 1064/ } \\
532 \mathrm{~nm}\end{array}$ & $\begin{array}{l}\text { Fixed in van at base of tower, telescope at } \\
4 \mathrm{~m} \text { ASL }\end{array}$ \\
\hline $\begin{array}{l}\text { D. Covert, }{ }^{\mathrm{b}} \text { T. Anderson, } \\
\text { S. Masonis }\end{array}$ & $\begin{array}{l}\text { TSI total and backscatter nephelometer }(450,550,700 \mathrm{~nm}) \\
\text { Beta } 180^{\circ} \text { lidar backscatter nephelometer; particle soot ab- } \\
\text { sorption photometer (PSAP); condensation nuclei }(\mathrm{CN}) \\
\text { counter }\end{array}$ & On tower at $7 \mathrm{~m}$ ( $9 \mathrm{~m} \mathrm{ASL})$ \\
\hline $\begin{array}{l}\text { A. Clarke, }{ }^{a} \text { V. Kapustin, }{ }^{a} \\
\text { K. Moore, }{ }^{\mathrm{a}} \text { S. Howell }{ }^{\mathrm{a}}\end{array}$ & $\begin{array}{l}\text { TSI integrating and backscatter nephelometer }(450,550,700 \\
\text { nm); laser optical particle counter }(0.1-5.0 \mu \mathrm{m}) \text {; differen- } \\
\text { tial mobility analyzer }(0.007-0.2 \mu \mathrm{m}) \text {; PSAP; aerodynam- } \\
\text { ic particle sizer (APS) }(0.7-10 \mu \mathrm{m}) \\
\text { Ceilometer (Vaisala, } 875 \mathrm{~nm}) \\
\text { Visibility sensor FD12P (Vaisala) }\end{array}$ & $\begin{array}{l}\text { In van sampling from tower with three inlets } \\
\text { cycled at } 5 \mathrm{~m}(7 \mathrm{~m} \text { ASL), } 10 \mathrm{~m}(12 \mathrm{~m} \\
\text { ASL), and } 20 \mathrm{~m}(22 \mathrm{~m} \mathrm{ASL}) ; \\
\text { Near tower at } 5 \mathrm{~m} \text { ASL } \\
\text { On tower at } 17 \mathrm{~m} \text { ASL }\end{array}$ \\
\hline $\begin{array}{l}\text { E. Saltzman, }{ }^{c} \text { A. Hynes, }{ }^{c} \\
\text { P. Campuzano }\end{array}$ & Aerosol sodium detector & In container sampling from tower at $12 \mathrm{~m}$ \\
\hline J. Porter ${ }^{\mathrm{a}}$ & Polar nephelometer (phase function) & Near tower, $4 \mathrm{~m} \mathrm{ASL}$ \\
\hline A. Hunt ${ }^{\mathrm{d}}$ & Bistatic nephelometer (532 nm) & $\begin{array}{l}\text { In van with sample line from tower at } 5 \mathrm{~m} \\
\text { (7 m ASL) }\end{array}$ \\
\hline K. Shifrin, ${ }^{\mathrm{e}}$ I. Zolotove & Theoretical analysis & Oregon State University \\
\hline
\end{tabular}

${ }^{a}$ University of Hawaii at Manoa

${ }^{\mathrm{b}}$ University of Washington

c The University of Florida

${ }^{d}$ Lawrence Berkeley National Laboratory

${ }^{\mathrm{e}}$ Oregon State University

height of the marine boundary layer by using a vertical firing minilidar $(905 \mathrm{~nm})$ system. A high-sensitivity retrieval algorithm provided by the manufacturer also allowed it to qualitatively map clouds, precipitation, and aerosol scattering at different altitudes with $30-\mathrm{m}$ resolution. A Vaisala visibility sensor (FD12P) was also mounted at $15 \mathrm{~m}$ on the BAFS tower (Fig. 2). This sensor uses $33^{\circ}$ forward scatter to obtain ambient inferred visibility. When pulses are also detected in the scattering volume it processes them to obtain a precipitation rate. A single-day comparison of raw visibility data and inverse ceilometer backscatter (low backscatter should correspond to high visibility) over the 15-30-m range shows a closely coupled relationship. Periods when sunlight contaminated the vertically pointing ceilometer data were excluded. Visibility data is the average of four 15-s data points, and ceilometer data is a 1-min average of multiple vertical shots. A direct comparison of these data in Fig. 2 shows a strong correlation in spite of the fact that visibility data are only for a scattering volume of about $1 \mathrm{~L}$ located at $15 \mathrm{~m}$, while the ceilometer data represents an average over $30 \mathrm{~m}(3-33 \mathrm{~m})$. This consistency indicates that both instruments can be calibrated to provide useful and quantitative data on ambient near-surface aerosol visibility and its variability, even in this clean marine setting. Although these devices were primarily used for continuous in situ characterization of aerosol structure during SEAS, similar good agreement with our nephelometer data (not shown) suggests that when aerosol characteristics are not highly variable (e.g., clean marine boundary layer) an effective ceilometer calibration is pos- sible over a vertical range in terms of aerosol extinction, thereby enabling visibility and extinction values to be estimated throughout the lower 1-2 km. Both instruments are autonomous and functioned continuously during most of SEAS (and for several weeks later) to provide continuous characterization of the boundary layer.

In spite of the remote location for SEAS in the central Pacific, these continuous data revealed variations in background marine aerosol that included evidence for long-range transport of continental aerosol (see section 4a). These unexpected changes in aerosol properties occurred toward the end of the 10-day SEAS intensive period. Continued sampling at the BAFS tower by UH after SEAS saw a return to typical conditions that helped us identify these changes as distinct from variability in the natural marine aerosol. We attribute these changes to earlier volcanic activity over Japan. This influence helped to explain some SEAS observations and demonstrated the ability of sources $10000 \mathrm{~km}$ distant to affect marine boundary layer aerosol. Because this event was revealed in various SEAS datasets discussed elsewhere and because it altered the background aerosol before reaching the coastal region, we will describe it below in addition to other more common influences upon coastal aerosol. The latter include issues that alter coastal aerosol production as well as characteristics associated with sampling protocol and location on the tower. These influences impact how various in situ instruments can be compared as well as how they can be related to remotely sensed data such as lidar. 

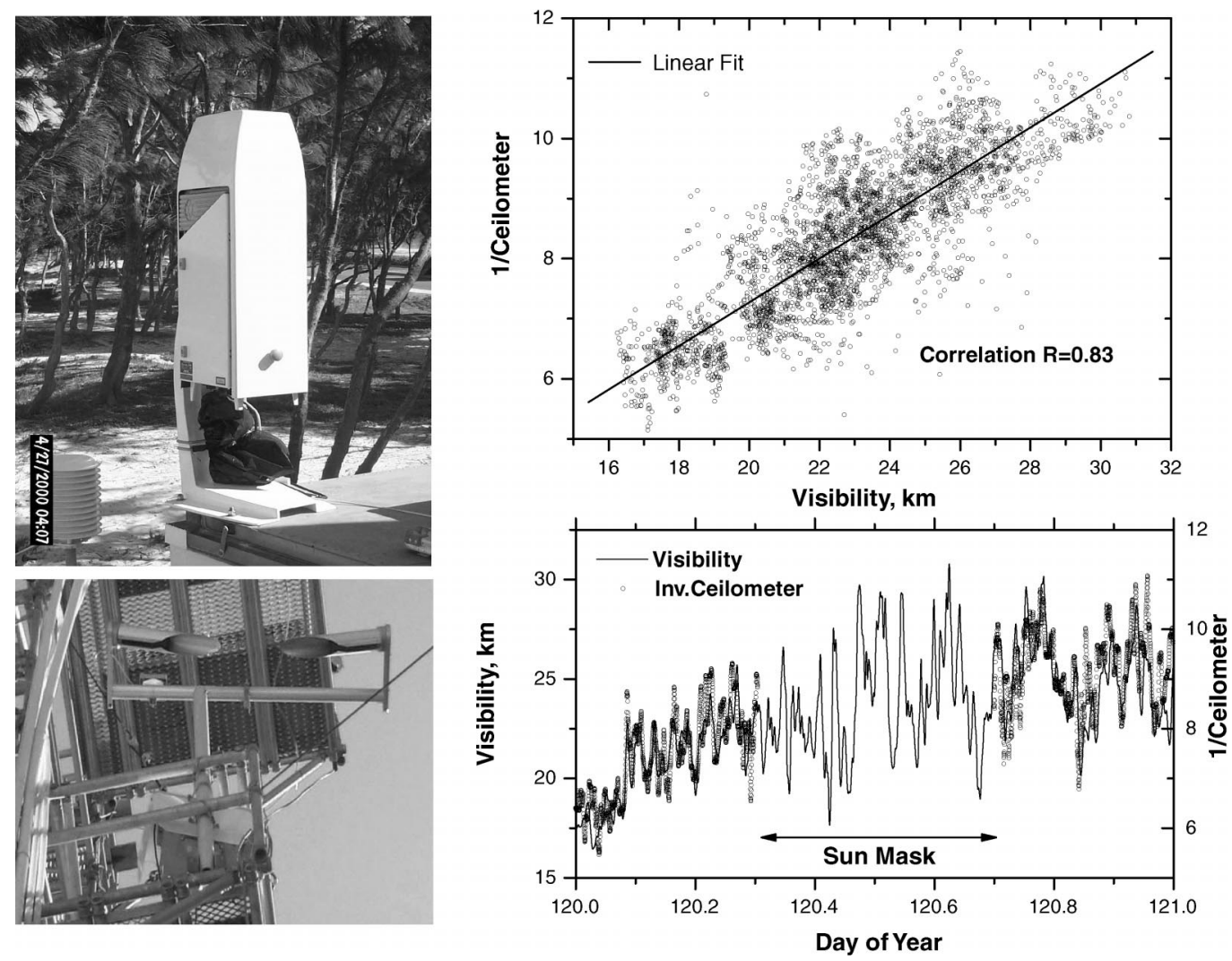

Fig. 2. (top left) Vaisala ceilometer mounted on portable laboratory and (bottom left) visibility monitor mounted at $10 \mathrm{~m}$ on BAFS tower. A comparison of $10-\mathrm{m}$ visibility from the Vaisala visibility sensor vs inverse ceilometer data (inverse extinction is a measure of visibility) collected from (top right) lowest altitude, 3-33-m bin and (bottom right) a 1-day time series of both (lower right), scaled here to reveal the overlap. The sun mask excludes ceilometer data when sunlight was contaminating the receiver.

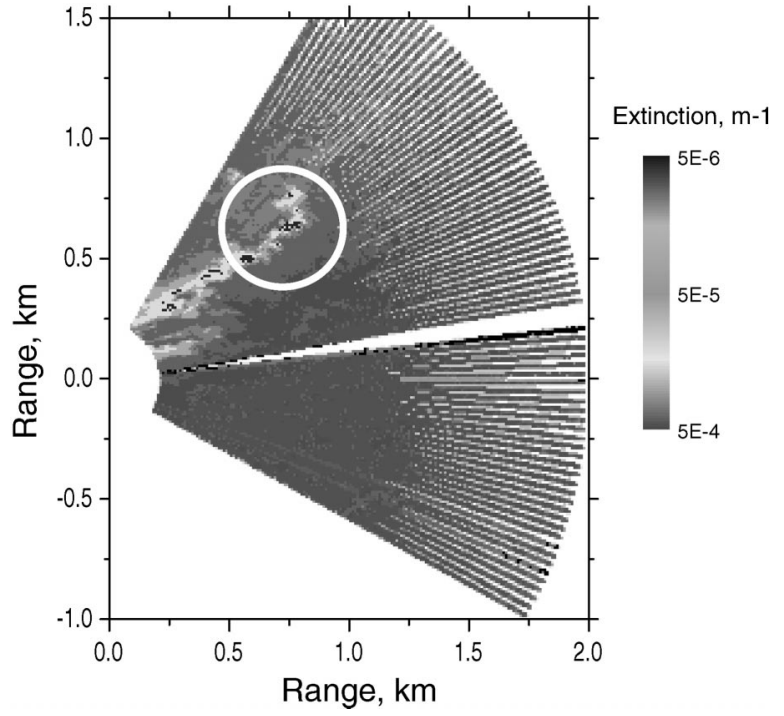

FIG. 3. Horizontal lidar scans (axes north and east, in km) over a $2-\mathrm{km}$ range at about 5-m altitude on 27 Apr 2000. A pronounced aerosol plume from the reef (circle) approaches the tower but most of the plumes pass just north of it. Dark radials are caused by interference by a cable in the field of view.

\section{The SEAS coastal aerosol field}

One objective of our earlier coastal measurement at BAFS and those made during the SEAS intensive was to establish links between remotely sensed lidar data and in situ measurements of the coastal aerosol. This requires not only recognition of the issues mentioned above that can affect the in situ data but also a strategy for comparing the in situ tower data collected along the wind vector passing the SEAS site to the larger field embraced by remote sensing. Figure 3 is one example of extinction derived from lidar backscatter as described in Porter et al. (2000; also see Porter et al. 2003). This was obtained during SEAS when winds were approaching the tower site from over the reef. The sea-salt plumes from the reef are structurally aligned with the prevailing wind, but they are temporally and spatially variable. When winds do not directly approach the tower from the reef, these plumes seen by the lidar will not be detected by the in situ measurements. Wind directions during SEAS (Fig. 4) were generally more easterly, suggesting that similar plumes often passed to the north of the tower. The situation is even more complex when vertical motions and variation in plume structure are 


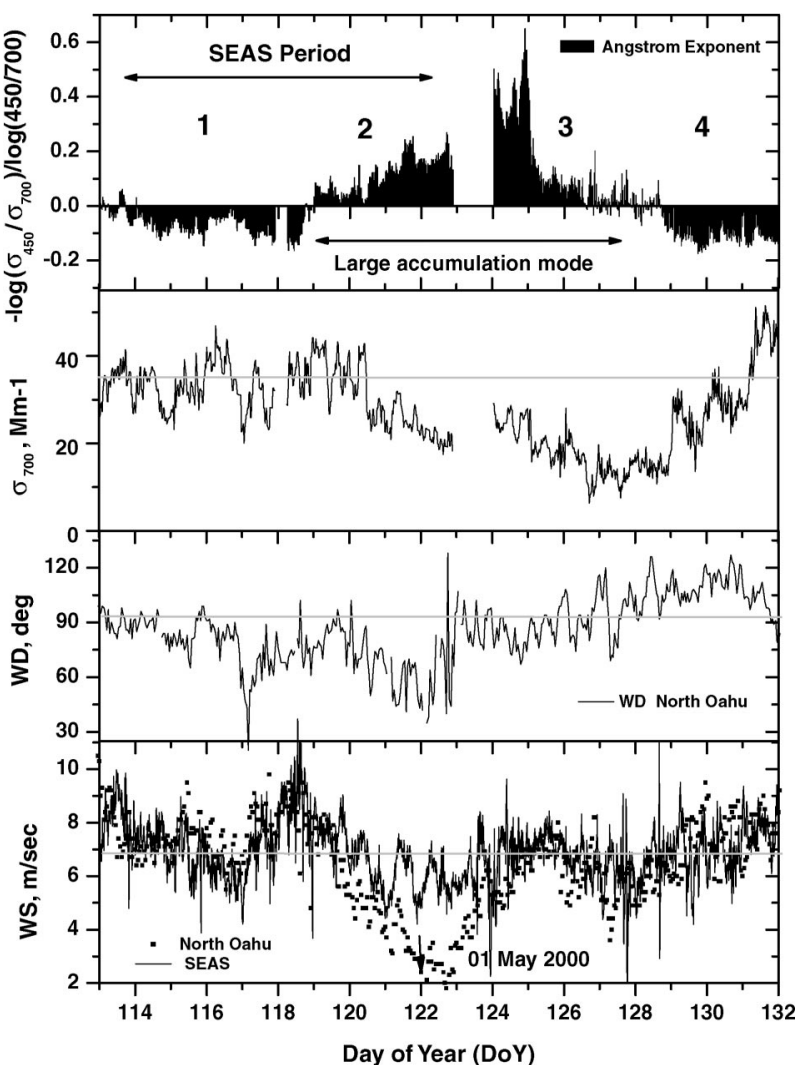

FIG. 4. Time series during and after the SEAS period showing anomalous increase in (top) Angström exponent linked to variations in the (top middle) scattering coefficient. (bottom middle) The wind direction north of Oahu. Note that (bottom) transitions to low winds measured north of Oahu are more pronounced than at SEAS site, consistent with their closer proximity to the high pressure system associated with this subsidence event (see Fig. 6 back trajectories).

considered (Porter et al. 2003). Hence, a long-term comparison of lidar data with in situ tower data from various heights both with and without coastal breaking wave influence was used to evaluate the lidar calibration (Clarke et al. 2003).

\section{a. Long-range transport and the Mt. Usu eruption}

It was initially presumed that the data collected during SEAS would be dominated by natural marine aerosol with fairly small variation in its characteristics, and for much of the time this was true. However, both the UH and UW nephelometer light-scattering data showed the unexpected change in the wavelength dependence during the SEAS period. The time series for these data are shown in Fig. 4, in which the wavelength dependence of scattering is shown in terms of the Angström exponent (Masonis et al. 2003), which reveals clear increases toward the end of the indicated SEAS period. This behavior implies significant variations in the relative concentrations of accumulation-mode and coarsemode aerosol. Figure 5 shows the average size distri-

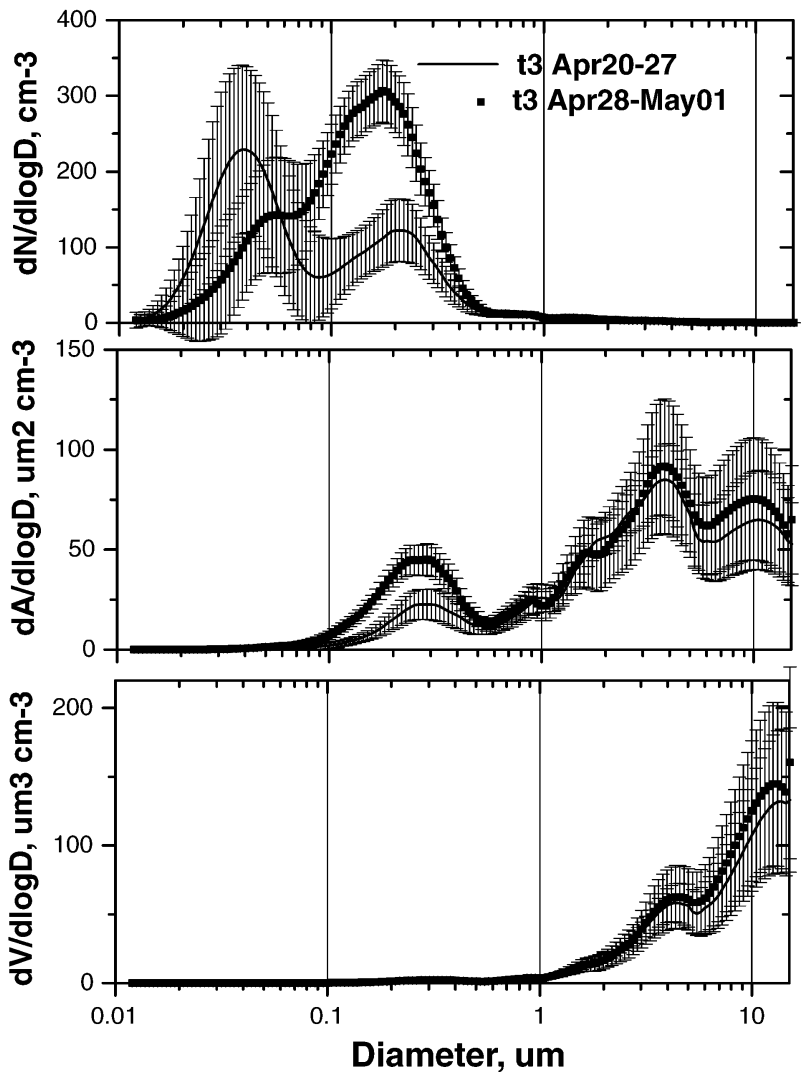

FIG. 5. Number, area, and volume distributions for averaged data collected at $20 \mathrm{~m}$ on the tower before and after the influence from a Mt. Usu eruption.

butions combined from a radial differential mobility analyzer (RDMA), laser optical particle counter (OPC), and aerodynamic particle sizer (APS) during SEAS before and after the transition on day of year (DOY) 118 (28 April). Size distributions have been adjusted to a common relative humidity $(\mathrm{RH})$ of $55 \%$ and shown as linear number, area, and volume. As RH increases, the aerosol diameters increase and result in increased extinction and changes in the wavelength dependency. After DOY 118 the number distribution reveals a decrease in the amplitude of the Aitken mode as well as an increase in the amplitude of the accumulation mode accompanied with shifts to smaller diameters. The coarse volume mode shows little change in average values before and after DOY 118. The area distribution best reflects the sizes influencing the optical properties, although the minimum near $6 \mu \mathrm{m}$, and the subsequent increase near $10 \mu \mathrm{m}$, is partly an artifact of the correction required for sampling and instrument behavior (Clarke et al. 2003).

These average differences, while not large, are consistent with changes in column aerosol properties evident in the ceilometer. Small trade wind clouds were nearly always present during SEAS; so, in order to better compare ceilometer data for several hours before and 
a

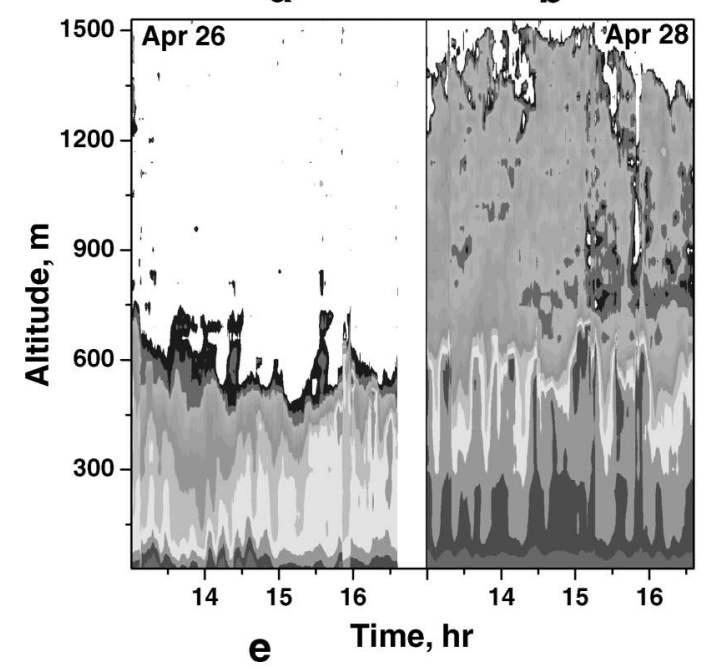

b

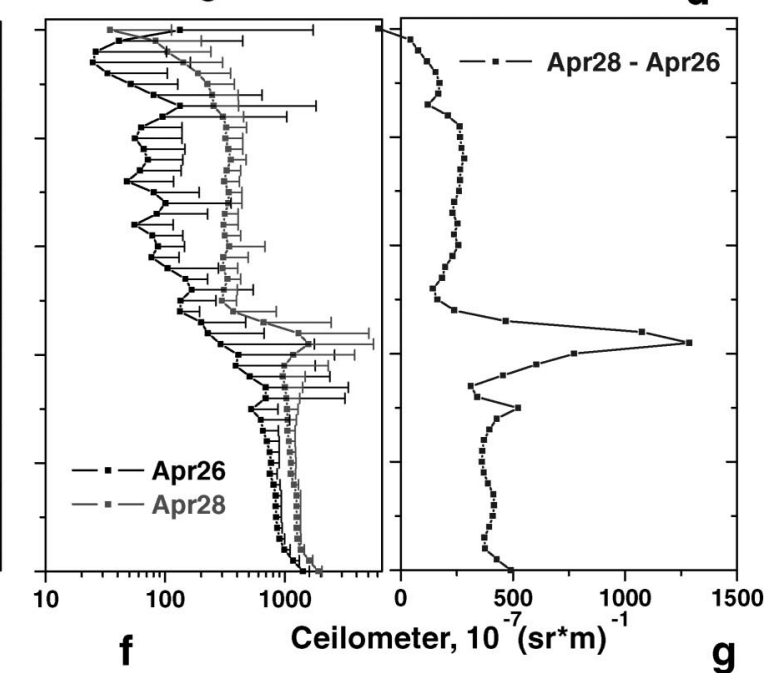

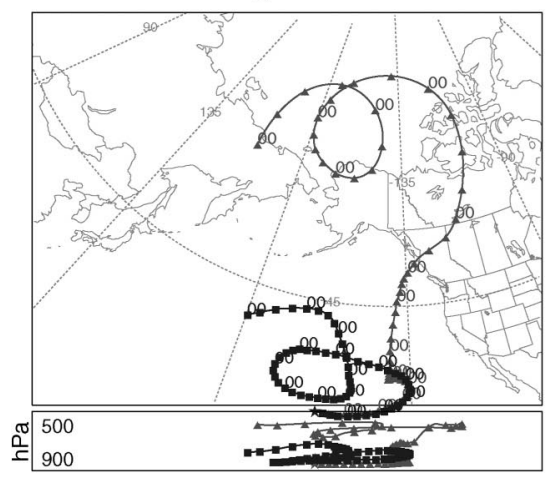
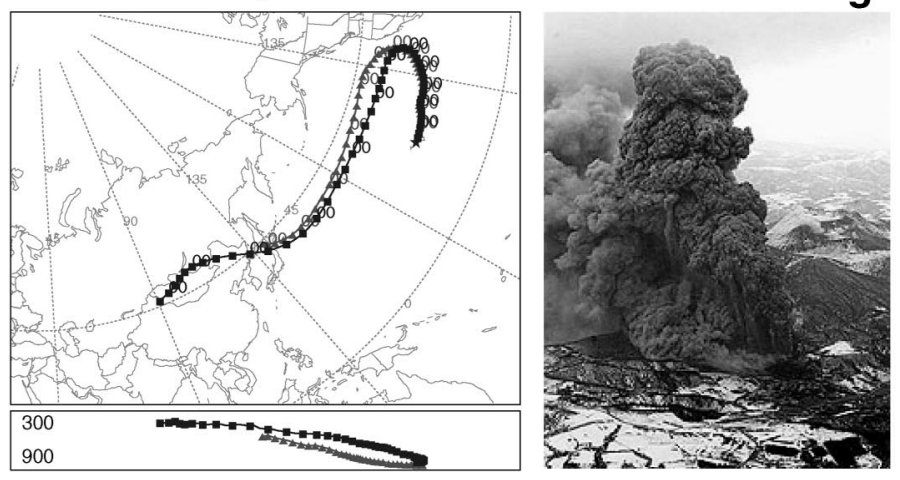

FIG. 6. Cloud-edited ceilometer data from (a) day before (26 Apr) and (b) day after (28 Apr) the most rapid change in aerosol properties suggest evidence emissions from Mt. Usu, (c) backscatter profiles before and after observed aerosol change, and (d) their difference, back trajectories from 100 and $500 \mathrm{~m}$ (e) before and (f) after change in aerosol, and the location and (g) image of vigorous ash eruption from Mt. Usu (early Apr).

after the transition day, DOY 118, we removed all intervals (every few minutes) at which clouds were present in order to generate cloud-free aerosol profiles for the marine boundary layer between the surface and 1500 $\mathrm{m}$. Comparison of about $4 \mathrm{~h}$ of ceilometer data before and after the transition day reveals that after DOY 118 the entire boundary layer has enhanced aerosol (Figs. $6 a, b)$. The difference in average profiles before and after this transition (Figs. 6d,c) also shows a peak near 600 $\mathrm{m}$, probably due to very high $\mathrm{RH}$ at altitudes generally near cloud. Otherwise the profile is fairly well mixed with higher ceilometer backscatter below cloud level due to aerosol growth in response to the higher $\mathrm{RH}$ generally present below cloud (Porter et al. 2003) compared to values above cloud.

Back trajectories [Hybrid Single-Particle Lagrangian Integrated Trajectory (HYSPLIT) model] obtained for the surface $(100 \mathrm{~m})$ and the "buffer" layer $(500 \mathrm{~m})$ before this period (Fig. 6e) are not indicative of a continental influence. However, similar back trajectories (Fig. 6f) during the period of perturbed sizes and optical properties all passed through the marine boundary layer inversion and went back over Japan in the free troposphere. The altitude of these trajectories passed over the Mt. Usu region, Japan, at about 4-5 $\mathrm{km}$ during the period of eruptive activity in April. Volcanic emissions were observed in the $800-3500-\mathrm{m}$ range during this period (Fig. 6g). Although trajectories were persistently from this region from DOY 119 to 125, given the uncertainty in 14-day back trajectories the exact location and altitude remain questionable. The difference in the size distributions (Fig. 4) demonstrates that the major change in scattering before and after DOY 118 is driven by the accumulation-mode diameters near $0.3 \mu \mathrm{m}$. Hence, we suggest that the changes observed in aerosol optical properties (Masonis et al. 2003; Clarke et al. 2003) are consistent with changes in the size distribution and with perturbations of the central Pacific marine boundary layer via long-range transport of volcanic aerosol from Japan. The trajectories suggest that this aerosol was transported in the free troposphere almost to California before subsiding through the Pacific high (Fig. 6f). It was then entrained into the marine boundary layer and transported by the trade wind flow toward 
TABLE 2. Processes affecting sea salt aerosol from breaking waves.

\begin{tabular}{|c|c|c|}
\hline Process & Condition & Result \\
\hline Background aerosol & Variable with a wind influence & $\begin{array}{l}\text { Dictates baseline aerosol upon which coastal effects are } \\
\text { superimposed }\end{array}$ \\
\hline Topographic influence & & $\begin{array}{l}\text { Nearshore and offshore topography have directional ef- } \\
\text { fects expressed at different sample altitudes on tower }\end{array}$ \\
\hline \multirow[t]{2}{*}{ Offshore wind } & $<7 \mathrm{~m} \mathrm{~s}^{-1}$ & New production low \\
\hline & $>7 \mathrm{~m} \mathrm{~s}^{-1}$ & New production increases from breaking waves \\
\hline Local wind direction & Over reef area & Increased sea-salt aerosol concentration \\
\hline \multirow[t]{3}{*}{ Local wind speed } & $<7 \mathrm{~m} \mathrm{~s}^{-1}$, not over reef & No additional production from wind-driven waves \\
\hline & $<7 \mathrm{~m} \mathrm{~s}^{-1}$, over reef & $\begin{array}{l}\text { Dilution effect }=>\text { waves act as line source resulting in } \\
\text { higher concentrations for lower wind speeds }\end{array}$ \\
\hline & $>7 \mathrm{~m} \mathrm{~s}^{-1}$ & $\begin{array}{l}\text { Increased whitecap production in lagoon as in open } \\
\text { ocean but increased dilution of coastal forced breaking } \\
\text { waves }\end{array}$ \\
\hline \multirow[t]{4}{*}{ Tide } & Low tide & Reef exposed $=>$ more breaking waves, more aerosol \\
\hline & Low tide & Coast break $=>$ smaller waves, less aerosol \\
\hline & High tide & Reef covered $=>$ less breaking waves, less aerosol \\
\hline & High tide & Coast break $=>$ larger waves, more aerosol \\
\hline \multirow[t]{2}{*}{ Wave height } & Low & Smaller breaking waves $=>$ less aerosol \\
\hline & High & Larger breaking waves $=>$ more aerosol \\
\hline \multirow[t]{2}{*}{ Boundar layer height } & Increase & Box size increases $=>$ lower concentration \\
\hline & Decrease & Box size decreases $=>$ higher concentration \\
\hline Entrainment & Variable & $\begin{array}{l}\text { Modification of near-surface aerosol by mixing with air } \\
\text { above inversion }\end{array}$ \\
\hline
\end{tabular}

Hawaii. The lower winds for the buoy north of BAFS during this period (Fig. 4) are consistent with high pressure subsidence nearby. This is similar to the subsidence and entrainment of Asian aerosol characterized recently from aircraft between Hawaii and California (Clarke et al. 2001).

\section{b. Other influences on coastal aerosol at BAFS}

Other temporal and spatial modifications of marine aerosol properties at BAFS are often related to environmental factors. Below we summarize a few results from related studies at BAFS prior to SEAS that reveal influences on aerosol concentrations or measurements at this site. In order to isolate and/or study any particular effect it is often necessary to carefully stratify data to isolate periods in which one influence is not confounded by others. Because of the complexity of interactions in a coastal setting, a clear dependency of aerosol properties on a single feature may not be revealed in a simple regression (Masonis et al. 2003).

Various SEAS investigators used a variety of inlets and sampling locations on the BAFS tower for their measurements. Given the proximity of breaking waves on the nearby shore and the more distant reef, the vertical position on the tower is an important consideration in terms of comparing any measurement. Also, for measurements made or averaged over different times, a number of the issues in Table 2 may need to be considered. In particular, for linking in situ data with the scanning lidar data focused 300-400 m offshore, many considerations may affect the comparison, since aerosol in the lidar viewing volume may or may not be reflected in observations at the tower (see Fig. 3). The wind di- rections evident in Fig. 4 suggest that plumes from the most active portion of the reef region (Fig. 3) will often pass north of the tower. This behavior and the site characteristics discussed below convinced us that our lidar evaluation should be based upon statistical comparisons involving maxima, minima, mean values, and their variance rather than short-period pointwise comparisons (Clarke et al. 2003). Table 2 identifies various influences upon the tower measurements for the SEAS campaign to be discussed more fully below.

\section{c. Offshore aerosol and winds}

Variations observed in marine aerosol at a coastal site include both local effects and the variability already present in the offshore aerosol. Under typical trade wind conditions at the SEAS site, the marine aerosol often shows no clear continental influence and is usually dominated by variations in production of aerosol from coastal and open-ocean breaking waves. These largely seasalt aerosols contribute most mass to the super micrometer size range that can significantly affect visible and infrared light extinction over the open ocean. Because open-ocean breaking waves are driven by surface wind speeds, we expect scattering and wind speeds to be related in regions where aerosol removal (e.g., precipitation) is not a strong and variable factor (Woodcock 1953; Guelle et al. 2001). Because both UH and UW measurements confirmed that light absorption during SEAS was far smaller than scattering (Masonis et al. 2003), we will consider total extinction and light scattering to be effectively the same in this paper.

The inverse of visibility measured by the Vaisala instrument is proportional to extinction due to scattering 

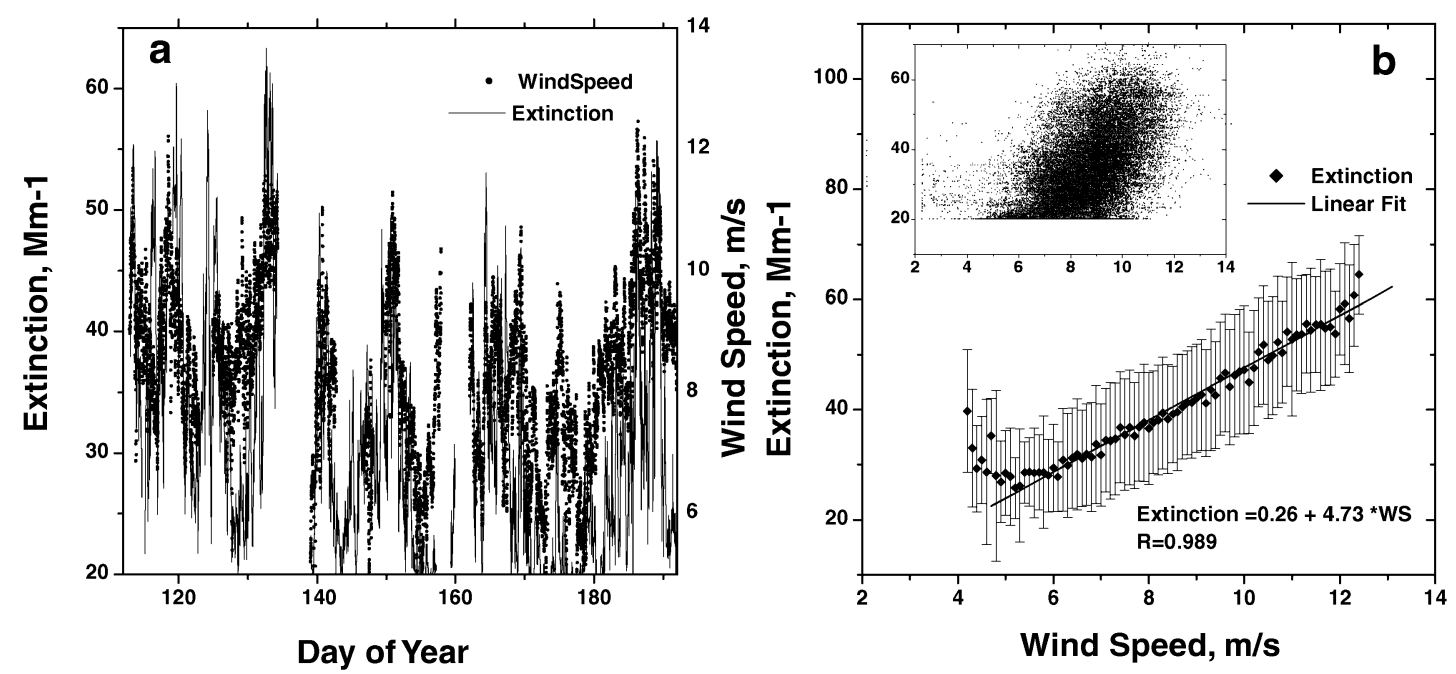

FIG. 7. (a) Time series showing similar variations of wind speed and filtered minimum extinction at BAFS over 80 days and (b) the relationship between average Vaisala-inferred extinction for binned wind speed with an inset showing the raw data.

and, because absorption is negligible, is identified here simply as extinction. Figure 7a shows the time series of wind speed and filtered extinction due to scattering from the Vaisala visibility sensor located at about $20 \mathrm{~m}$ on the tower. These were measured for 80 days, from 19 April 2000 (DOY 110) to 11 July 2000 (DOY 193) and include the SEAS period (DOY 110-120). These data were filtered after applying a 25-point ( $6 \mathrm{~min})$ lowpass box filter to the data. This reduced the influence of plumes from coastal breaking waves that are often on the order of a minute long (Clarke et al. 2003) in order to better represent open-ocean visibility values.

This time series demonstrates that many longer-period variations in extinction measured at the site are coupled to variations in wind speed. A scatterplot of this data for the entire 80-day period is shown as an insert in Fig. 7b and suggests a wind speed dependence but with a large variability indicative of other processes influencing extinction. Because wind speeds were not equally distributed over the range of observed values, we have used these data to calculate the mean and standard deviation of this extinction for each interval of $0.1 \mathrm{~m} \mathrm{~s}^{-1}$ of wind speed shown in Fig. 7b. The resulting slope reveals a very clear dependence of extinction on wind speed. However, below $6 \mathrm{~m} \mathrm{~s}^{-1}$ extinction is higher than this dependence would suggest. This is due in part to limitations of the visibility sensor under low-extinction conditions but may also reflect the possible increase in coastal aerosol concentrations under low-wind conditions. This can be caused by reduced dilution of aerosol produced from coastal breaking waves (see section 4e). Nevertheless, this figure reveals that increased wind speed is a major influence on coastal light scattering upon which other significant influences are superimposed.

Additional verification of the utility of the Vaisala visibility sensor as a continuous measurement indicative of ambient extinction is confirmed by comparison to nephelometer data taken from an aspirated inlet at the top of the tower (Fig. 8a). Here nephelometer scattering values corrected to ambient conditions (Clarke et al. 2003) are plotted with filtered Vaisala minimum estimated extinction for a 5-week period. When visibility exceeds $50 \mathrm{~km}$ the visibility sensor is at its detection limit and does not record data such that extinction values derived from inverse visibility do not exist for values less than $20 \mathrm{Mm}^{-1}$. Good agreement between the two instruments is evident except toward the end of the period, when Vaisala extinction values trend higher because of failure to clean the optical lenses. A scatterplot (Fig. 8b) of this Vaisala-inferred extinction and nephelometer scattering confirms a strong relationship between the two measurements. Deviations are most evident at the lowest extinction values near the Vaisala detection limit and for the highest extinction cases observed when the lenses were not clean. Other reasons for differences can arise due to different tower locations or changes in the phase function of the size distributions. However, the overall performance of this autonomous off-the-shelf instrument in a challenging environment confirms that it provides a reasonable measure of in situ scattering well above its detection limit, even in the remote clean Pacific atmosphere.

\section{d. Effects of coastal wind direction}

Because of the variation in offshore topography described above we might expect that the effects of breaking waves will be more pronounced when winds originate from the islands to the northeast or reef areas. In Fig. 9a we have stratified nephelometer scattering data collected at the top of the tower for periods with excursions in wind direction but only modest variation in 

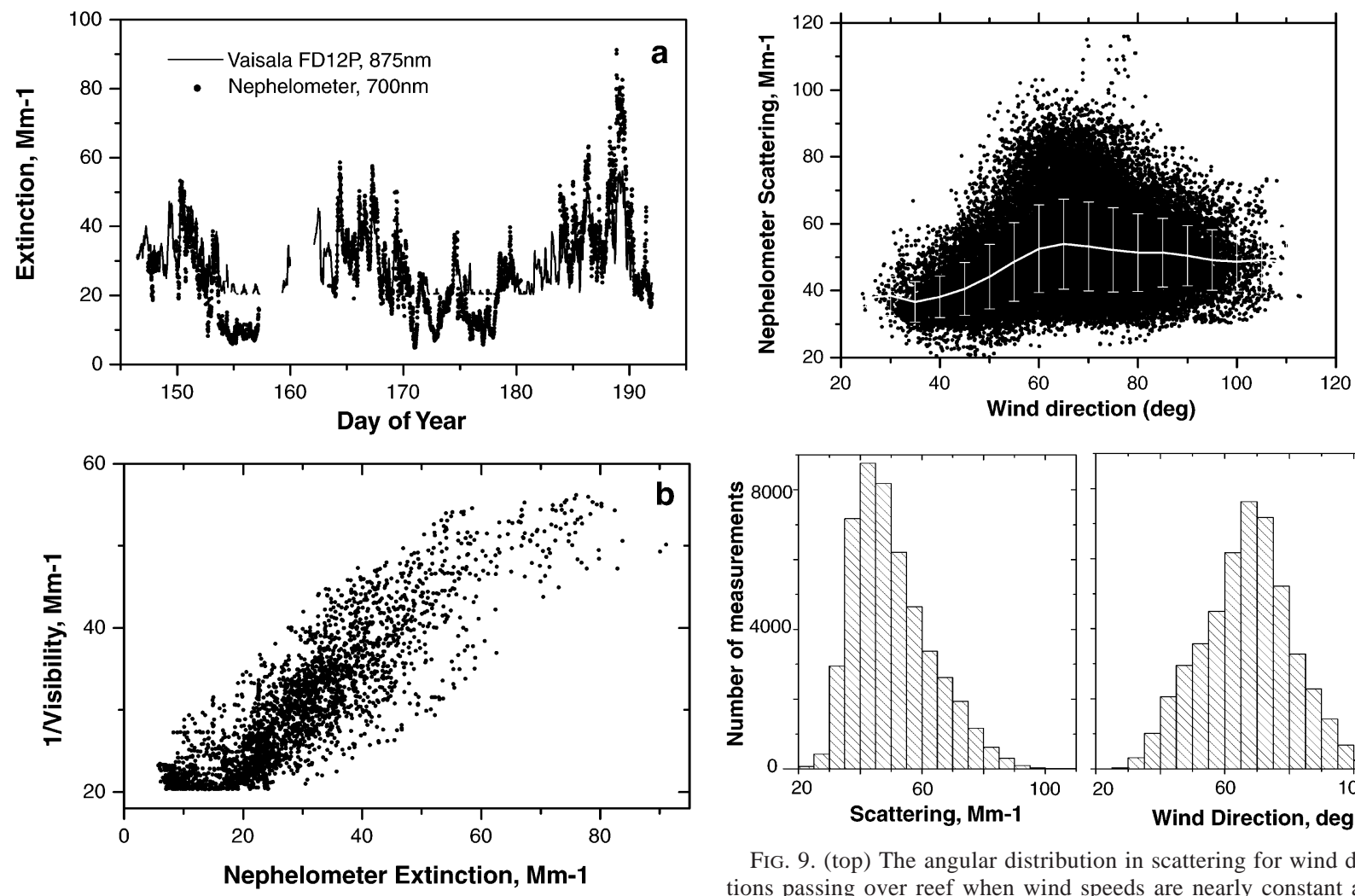

FIG. 8. (a) Time series of Vaisala-inferred extinction and nephelometer extinction and (b) relationship between Vaisala-inferred extinction and nephelometer extinction.

speed $\left(6-8 \mathrm{~m} \mathrm{~s}^{-1}\right)$. The top of the tower is rarely influenced by waves breaking on the adjacent beach (see below). This plot suggests that wind directions between about $55^{\circ}$ and $80^{\circ}$ yield typical enhancements in aerosol scattering at the BAFS SEAS site. This enhancement corresponds to the location of the extended "reef" region about $1 \mathrm{~km}$ away, as indicated in Fig. 1. The contribution of the reef to enhanced scattering will also depend upon various additional factors, including tides, swell, wind speed, wind variation, and turbulent mixing. The superimposed plot of mean and standard deviation of the scattering values shows a relatively smaller increase than the envelope of points might suggest. This is understandable when the frequency distribution of scattering and wind directions are examined (Fig. 9b). This enhancement will be even greater for locations closer to the reef, since mixing and dispersion will tend to reduce concentrations during passage to the SEAS site (Porter et al. 2003). The most common wind directions are from $55^{\circ}$ to $80^{\circ}$ while those cases when scattering exceeds $70 \mathrm{Mm}^{-1}$ occur less than $10 \%$ of the time. One could argue that these are more evident in the $55^{\circ}-80^{\circ}$ angles simply because these variable winds are more common from that direction. However, the relative absence of high values outside of that angular
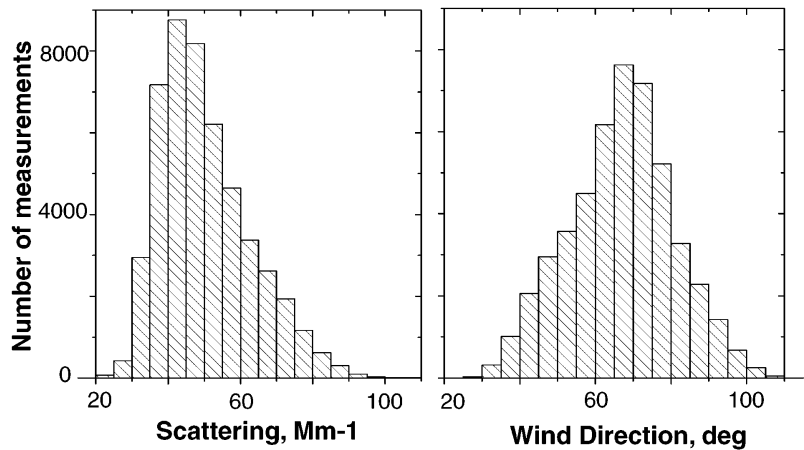

FIG. 9. (top) The angular distribution in scattering for wind directions passing over reef when wind speeds are nearly constant at 6$8 \mathrm{~m} \mathrm{~s}^{-1}$ and (bottom) histograms of the scattering and wind direction values.

range is consistent with the reef playing a role in the enhanced scattering.

\section{e. Wind-induced aerosol dilution}

In contrast to the effect of increased sea-salt production over the open ocean due to wind speeds rising above 7-8 $\mathrm{m} \mathrm{s}^{-1}$ (Woodcock 1953; Monahan et al. 1983), there is an opposite effect of aerosol production generated from coastal breaking waves. When wave breaking occurs due to interaction of the wave field and coastal topography, it is physically induced and not directly driven by the wind field. The effect of increasing wind is to pass more air over the source region per unit time such that concentrations of wave-generated aerosol are mixed into large air volumes (diluted) with increasing wind speed (ignoring other production effects at higher wind speeds).

This behavior is evident for $2.5 \mathrm{~h}$ of data collected at BAFS on DOY 98 for wind speeds varying from 5.5 to $9 \mathrm{~m} \mathrm{~s}^{-1}$ (Fig. 10a). The 5-m scattering values (Fig. $10 \mathrm{~b}$ ) and the wind speeds tend to vary inversely with lower wind speeds having the highest scattering, in contrast to open-ocean behavior. Under appropriate conditions, the variation in contributions to scattering from coastal breaking waves (or reef waves) should be predictable for similar conditions and could be described 

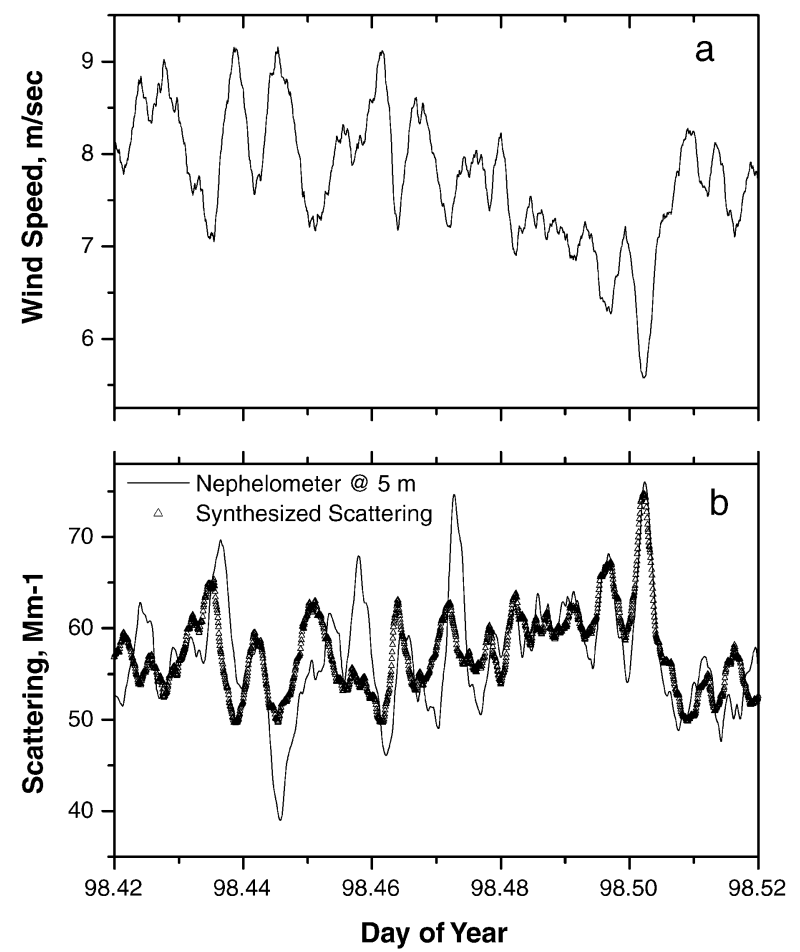

FIG. 10. (a) Time series of nephelometer scattering and variations in low wind speed and (b) comparison of measured and synthesized nephelometer scattering.

by a nearly constant source term modulated (diluted) by a variable wind speed. To test this we took the average scattering value and the average wind speed value for this period and assumed that coastal breaking waves behave as a constant line source of aerosol. We then use the ratio of instantaneous wind speed to the average wind speed in order to describe relative wind fluctuations over the period.

When this instantaneous ratio is divided into the average scattering value for the period, it provides a synthesized wind-modulated scattering value. An increase (decrease) in instantaneous wind would decrease (increase) this synthesized scattering in proportion to the wind speed. Figure $10 \mathrm{~b}$ reveals that during this period this synthesized scattering is generally representative of ambient scattering values. Clearly, both the short- and long-term fluctuations are largely explained simply by the dilution effect of a variable wind speed passing over a mechanically (wave) driven line source upwind. This behavior will be similar for both the off-shore reef source and the coastal breaking-wave source. Furthermore, when offshore winds increase and offshore scattering increases (as in Fig. 7) the local wave-breaking intensity can increase with wave amplitude, but this contribution will also be diluted by the higher winds. Hence, wind-wave interaction and aerosol production in a coastal setting can be far more complex than expected for the open-ocean case.

\section{f. Other effects}

Under conditions of nearly constant wind direction, the modulation in scattering at the BAFS SEAS site is also driven by additional effects. These can result in different influences for near-shore waves and those on the outer reef. For example, the outer reef is more exposed when the tide lowers and more wave energy is dissipated by waves breaking on the reef. However, as the tide rises, fewer waves break on the outer reef, allowing more wave energy to pass the reef to result in enhanced wave breaking along the shoreline. Hence the interaction of tides and topography can modulate the location where wave energy is dissipated and where aerosol production is favored.

Separate tower profiles (not shown) obtained from an instrument package hoisted up and down the tower also confirmed that aerosol generated by the near-shore breaking waves was generally well below $10 \mathrm{~m}$ at the tower location. This was also consistent with alongshore lidar measurements of plume structure (Porter et al. 2003) that showed that coastal plumes from breaking waves passed over the beach below about $5 \mathrm{~m}$. Additional concurrent nephelometer measurements at $1 \mathrm{~m}$ above surface over the land downwind of the beach also showed that downwind turbulence induced by the tree line (circled tower region in Fig. 1a) exponentially eroded these near-surface plumes to near-background values in about $300 \mathrm{~m}$. More complex interactions involving strong near-surface production and accumulation in conjunction with strong vertical dilution and mixing can be expected when winds move nearly parallel to the trees along the shoreline. Fortunately, the winds during the SEAS period were primarily onshore.

\section{Summary}

The BAFS coastal tower in Hawaii was selected for SEAS as a generally clean, unpolluted coastal site in the central Pacific. The presence of steady trade winds also provided more predictable conditions and a marine aerosol that exhibited less variability than many other locations. This low variability was desirable for testing and comparing various new aerosol instruments during SEAS. Even so, both long-range transport from the continents and various local effects were identified and found to significantly influence aerosol physical and optical properties at the site. Various studies prior to SEAS revealed that topography, wind direction, wind speed, and sample altitude all affected measured aerosol concentrations. These data emphasize the importance of characterizing a coastal site and the desirability of comparing measurements only over similar times and similar altitudes on the sampling tower. When the latter is not always possible, such as the comparison of tower data to offshore lidar measurements, then different strategies for recognizing and accounting for these various effects need to be considered. 
SEAS also provided an opportunity for deployment and testing of new autonomous measurements from a Vaisala ceilometer and visibility sensor. It was found that the visibility sensor could provide quantitative continuous measurements of visibility that could be used to estimate ambient extinction. We also demonstrated that the ceilometer, when operated in high-sensitivity mode, produced near-surface data that could be quantitatively linked to measured extinction and suggests that appropriate range calibration may allow column extinction data to be similarly quantified. Both instruments were found to be rugged tools that could provide continuous information on ambient aerosol optical properties in the marine boundary layer and require little maintenance. These features allowed them to provide a valuable context for the other SEAS measurements and also make them attractive choices for low-maintenance shipboard deployment.

Acknowledgments. We extend special appreciation to Drs. R. Ferek and S. Ackleson of the Office of Naval Research for their support (N00014-96-1-0320) of our long-term measurements at BAFS and for the SEAS experiment described here. We also thank B. Lienert and S. Sharma for their lidar image of plumes from breaking waves, and S. Howell, K. Moore, M. Pinkerton, and B. Hallmark for assistance in data collection and processing.

\section{REFERENCES}

Campuzano-Jost, P., and Coauthors, 2003: Near-real-time measurement of sea-salt aerosol during the SEAS campaign: Comparison of emission-based sodium detection with an aerosol volatility technique. J. Atmos. Oceanic Technol., 20, 1421-1431.

Clarke, A. D., 1991: A thermo-optic technique for in-situ analysis of size-resolved aerosol physicochemistry. Atmos. Environ., 25A, 635-644.

_ V. Kapustin, W. Collins, P. Rasch, K. Moore, S. Howell, and H. Fuelberg, 2001: Dust and pollution transport on global scales: Aerosol measurements and model predictions. J. Geophys. Res., 106, 32 555-32 569 .

- - - S. Howell, K. Moore, B. Lienert, S. Masonis, T. Anderson, and D. Covert, 2003: Sea-salt size distributions from breaking waves: Implications for marine aerosol production and optical extinction measurements during SEAS. J. Atmos. Oceanic Technol., 20, 1362-1374.

Guelle, W., M. Schultz, Y. Balkanski, and F. Dentener, 2001: Influence of the source formulation on modeling the global distribution of sea-salt aerosol. J. Geophys. Res., 106, 27 509-27 524.

Lienert, B. R., J. N. Porter, and S. K. Sharma, 2003: Aerosol size distributions from genetic inversion of polar nephelometer data. J. Atmos. Oceanic Technol., 20, 1403-1410.

Masonis, S., T. Anderson, D. Covert, V. Kapustin, A. Clarke, S. Howell, and K. Moore, 2003: A study of the extinction-to-backscatter ratio of marine aerosol during the Shoreline Environment Aerosol Study. J. Atmos. Oceanic Technol., 20, 1388-1402.

Monahan, E. C., C. W. Fairall, K. L. Davidson, and P. J. Boyle, 1983: Observed inter-relations between $10 \mathrm{~m}$ winds, ocean whitecaps and marine aerosols. Quart. J. Roy. Meteor. Soc., 109, 379-392.

Porter, J. N., B. Lienert, and S. K. Sharma, 2000: Using horizontal and slant lidar measurements to obtain calibrated aerosol scattering coefficients from a coastal lidar in Hawaii. J. Atmos. Oceanic Technol., 17, 1445-1454.

_ $, \ldots, \ldots$, E. Lau, and K. Horton, 2003: Vertical and horizontal aerosol scattering fields over Bellows Beach, Oahu, during the SEAS experiment. J. Atmos. Oceanic Technol., 20, 13751387.

Shifrin, K. S., and I. G. Zolotov, 2003: The use of direct observations over the aerosol particle size distribution for inverting lidar data. J. Atmos. Oceanic Technol., 20, 1411-1420.

Woodcock, A. H., 1953: Salt nuclei in marine air as a function of altitude and wind force. J. Meteor., 10, 362-371. 